\section{Cureus}

Received 12/26/2015

Review began 12/29/2015

Review ended 01/11/2016

Published 01/27/2016

\section{(c) Copyright 2016}

Loomba et al. This is an open access article distributed under the terms of the Creative Commons Attribution License CC-BY 3.0., which permits unrestricted use, distribution, and reproduction in any medium, provided the original author and source are credited.

\title{
Radiologic Considerations in Heterotaxy: The Need for Detailed Anatomic Evaluation
}

\author{
Rohit Loomba ${ }^{1}$, Parinda H. Shah ${ }^{2}$, Robert H. Anderson ${ }^{3}$, Yingyot Arora ${ }^{4}$ \\ 1. Department of Cardiology, Children's Hospital of Wisconsin 2. Department of Radiology, Advocate \\ Illinois Masonic Medical Center 3. Institute of Genetics, Newcastle University 4. Biomedical Sciences, \\ Denver University
}

$\square$ Corresponding author: Rohit Loomba, rloomba@chw.org

Disclosures can be found in Additional Information at the end of the article

\section{Abstract}

So-called "heterotaxy" is a laterality defect characterized by isomerism of the thoracic organs and random arrangement of the abdominal organs. These findings go beyond anatomic curiosity and have functional implications. It is, thus, of the utmost importance to be able to properly identify these findings.

Radiologic studies can be invaluable in determining anomalies in the central nervous, pulmonary, cardiovascular, gastrointestinal, genitourinary, and immunologic systems in patients with isomerism. Here, we review findings associated with isomerism and their importance in the setting of isomerism with the aim of ensuring that radiologists effectively describe findings in these patients and that cardiologists understand the wide variety of congenital malformations that may be present.

Categories: Pediatrics, Radiology

Keywords: heterotaxy, isomerism, malrotation, univentricular, single ventricle, congenital, spleen, bronchial, neural

\section{Introduction And Background}

So-called "heterotaxy" is a laterality defect characterized by isomerism of the thoracic organs and random arrangement of the abdominal organs. From the stance of the cardiologist, it is present when an intracardiac abnormality is associated with bronchial isomerism or abnormal arrangement of the abdominal organs, particularly the spleen. Heterotaxy, however, can affect any system of organs, and can be found with normal intracardiac structure. The visceral effects go beyond being simply anatomic, with functional implications involving several organ sytems, a point best demonstrated by the fact that absence of the spleen, multiple spleens, or even a normally located and solitary spleen all can be associated with abnormal splenic function in the setting of heterotaxy [1].

Historically, heterotaxy has been segregated on the basis of splenic anatomy with patients being classified has having asplenia or polysplenia. This approach is not ideal, as a non-trivial proportion of patients with heterotaxy have solitary spleens, while correlation between absence of the spleen, or multiple spleens, with findings in the other systems is far from perfect. Additionally, it is now recognized that heterotaxy is better segregated on the basis of isomerism of the atrial appendages rather than other features such as splenic anatomy as it is the atrial appendage morphology that is the most constant feature and offers the most consistent “syndromic clustering" [2-4]. Knocking out the Pitx1 or Cited-1 genes in mice, for example, has 
now been shown to lead to isomerism of the right atrial appendages, while knocking out the Lefty-1 or sonic hedgehog genes has been shown to lead to isomerism of the left atrial appendages [3, 5-7]. Distinguishing the subsets on the basis of isomerism is important as those with right isomerism have been demonstrated to have higher rates of infection and mortality, specifically postoperative mortality in patients with functionally univentricular hearts [8]. To date, however, it has proved difficult to visualize the atrial appendages echocardiographically, so that atrial appendage morphology often must be inferred in the context of associated findings. As already emphasized, it is also the case that some patients with heterotaxy have usual arrangement, or mirror-imagery, of the atrial appendages, although this represents less than $1 \%$ of all reported cases [9-11].

In general, patients with right isomerism have more complex cardiovascular malformations, often necessitating functionally univentricular palliation, along with absence of the spleen, totally anomalous pulmonary venous connections even if the pulmonary veins return to the heart, and intestinal malrotation. Those with left isomerism generally have less complex cardiovascular malformations, with multiple spleens, and interruption of the inferior caval vein $[12,13]$. Arrhythmias can be present in both right and left isomerism [14, 15]. Thrombocytosis may also be present in either subset in those with functionally univentricular hearts $[16,17]$.

Patients with heterotaxy often undergo extensive medical evaluation, including imaging, it is important, therefore, for radiologists to be aware of heterotaxy and its associated findings. A thorough understanding of the manifestations of heterotaxy makes its diagnosis more likely, and thus allows for complete evaluation of associated abnormalities. This fact is also of significance, since in the past the syndromes have been described in terms of "situs ambiguus." Simple description of the findings in the various systems removes any potential ambiguity. We provide here a review of the findings associated with heterotaxy, suggest appropriate strategies for imaging, and provide information that is vital to determining optimal clinical management.

\section{Review}

\section{Cardiovascular malformations}

A variety of cardiovascular malformations is to be expected in patients known to have heterotaxy. In this review, we discuss both intracardiac lesions and abnormalities of systemic and pulmonary venous return. Evaluation of intracardiac anatomy, nonetheless, is primarily the task of cardiologists, so our discussion on cardiovascular malformations will be limited.

Those with right isomerism are more likely to have a common atrioventricular junction guarded by a common valve, double inlet left ventricle, double outlet right ventricle, an absence of the coronary sinus, and left-handed ventricular topology. The totally anomalous pulmonary venous connection will always be present when patients have bilateral appendages of right morphology, but the pulmonary veins connect to an extracardiac site in half the cases.

Discordant ventriculoarterial connections are also frequent, and pulmonary stenosis or atresia is to be anticipated. Those with left isomerism are more likely to have aortic stenosis, isolated atrial and ventricular septal defects, as well as bilateral connections of the pulmonary veins. Interruption of the inferior caval vein is more common in those with isomeric left atrial appendages [7]. A significant proportion will again have an atrioventricular septal defect with a common atrioventricular junction, but more usually with biventricular and mixed atrioventricular connections.

The precise intracardiac diagnosis need not be made by the radiologist, although characteristic radiologic findings of specific cardiovascular malformations may be apparent on the chest radiograph. More importantly, however, is an evaluation of the pulmonary vasculature and the 


\section{Cureus}

lung fields. Based on the physiology resulting from the particular cardiovascular malformation, patients will either have oligemia or hyperemia noted on their chest radiograph, which can help narrow down the diagnosis and help guide clinical decision-making, particularly in the setting of heart failure. Oligemia will often be the result of pulmonary stenosis or atresia existing in the settings of tetralogy of Fallot or a double-outlet right ventricle with subaortic interventricular communication. Hyperemia, in contrast, will often be the result of lesions, such as hypoplastic left heart syndrome or double outlet right ventricle, with subpulmonary interventricular communication [18].

The chest radiograph can also be useful in helping to raise the suspicion of a totally anomalous pulmonary venous connection, particularly of the supracardiac and cardiac varieties. When the pulmonary veins are returning to the right side of the heart, this can cause enlargement of the right-sided atrium and right ventricular hypertrophy and dilation. Increased flow of blood to the lungs in this setting also leads to pulmonary and interstitial edema, producing the characteristic "snowman in a snowstorm" appearance. Obstruction of the pulmonary venous connections may result in the very sudden opacification of the lung fields bilaterally, and should prompt immediate further investigation [18-19].

The likely presence of anomalous pulmonary venous connections emphasizes the role of computed tomography and magnetic resonance imaging. These modalities should delineate the course of the veins and show their exact sites of cardiac or extracardiac connection. This information is important for the cardiothoracic surgeon, who needs to know if rapid intervention on the pulmonary veins is necessary. Computed tomography offers a quicker study, although at the expense of exposure to radiation while magnetic resonance imaging offers a radiation-free alternative at the expense of greater study times and the likely need for sedation in infants [19-20]. In Figure 1, we show how magnetic resonance delineated a totally anomalous pulmonary venous connection in the setting of right isomerism to a confluence that drains into the left-sided atrium.

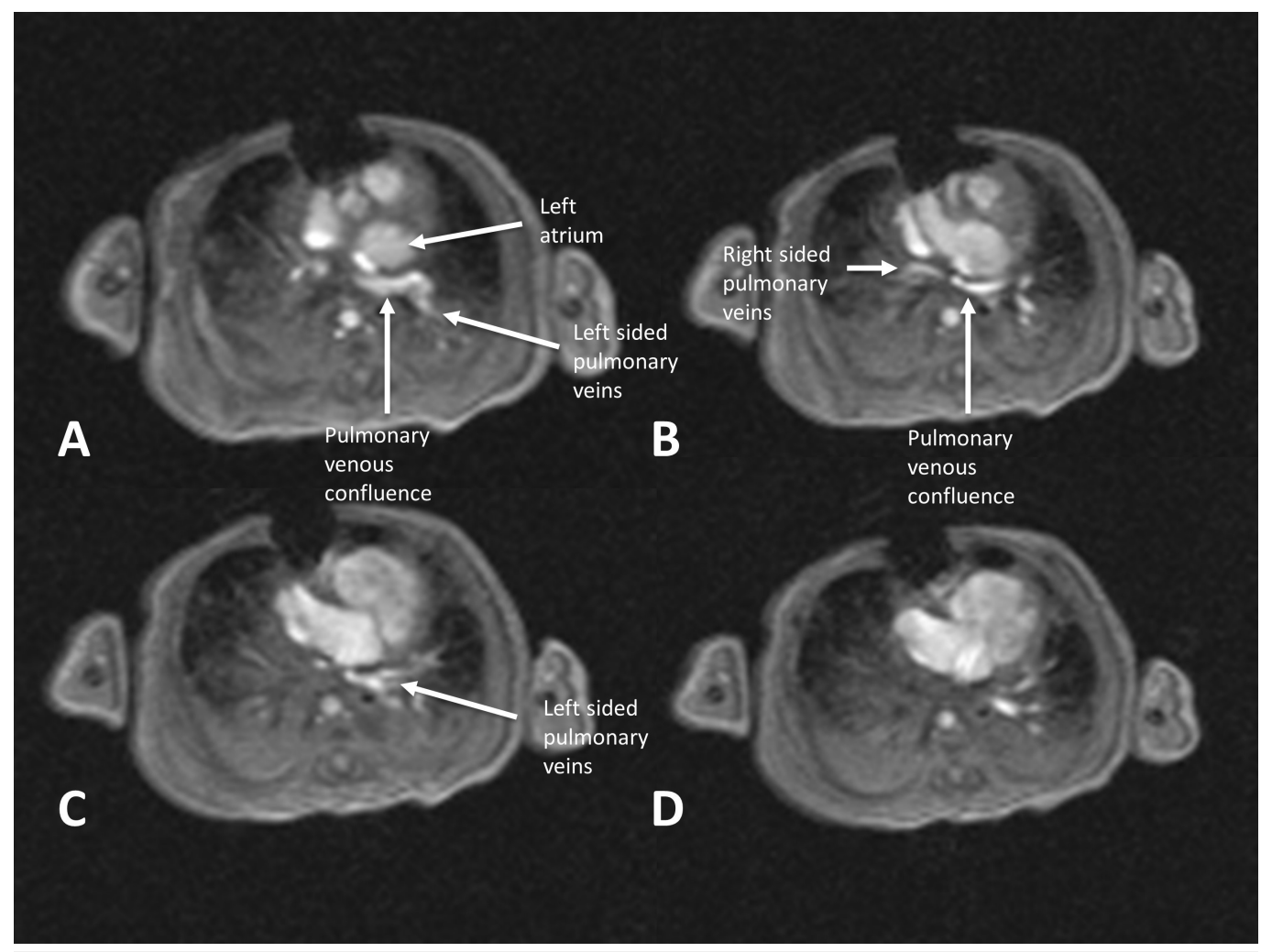

FIGURE 1: Anomalous pulmonary venous connection 


\section{Bronchial and pulmonary abnormalities}

As with the atrial appendages, both the bronchi and lungs are also usually isomeric in the setting of so-called heterotaxy. Van Mierop and colleagues were the first to recognize bronchial isomerism, a point later confirmed by studies done by Landing, et al. and Partridge, et al. [2124]. Most recently, our group has confirmed their findings [25]. Bronchial isomerism is easily assessed by comparing bronchial lengths. A ratio of bronchial lengths less than 1.5 is indicative of bronchial isomerism [24]. Once bronchial isomerism is confirmed, right isomerism can be distinguished from left isomerism by measuring the bronchial angles. Angles less than 135 degrees are consistent with left isomerism while angles greater than 135 degrees indicate right isomerism. Measurements can be made on a chest radiograph or angiography in which the bronchi are visible, as well as by chest tomography or magnetic resonance imaging. Correlation between the various modalities is good, but may not always lead to the same decision. In this situation, an average of all modalities can reasonably be used. Partridge, et al. normalized bronchial length to tracheal width as a means of differentiating the isomeric subsets, although this was not confirmed in one study [24].

We found the bronchial angle to be $75 \%$ sensitive and $93 \%$ specific in determining left isomerism. The negative and positive predictive value of bronchial isomerism in predicting isomerism of the left atrial appendages was $69 \%$ and $70 \%$, respectively. In respect to determining isomerism of the right atrial appendages, right bronchial isomerism was $93 \%$ sensitive and $75 \%$ specific, with an $80 \%$ and $60 \%$ negative and positive predictive value, respectively. In Figure 2, we show examples of bronchial isomerism. In our analysis, nonetheless, we found discordances between bronchial isomerism and presumed isomerism of the atrial appendages in roughly one-fifth of patients. The clinical significance of such discordances is unclear at this time [25]. 


\section{Cureus}

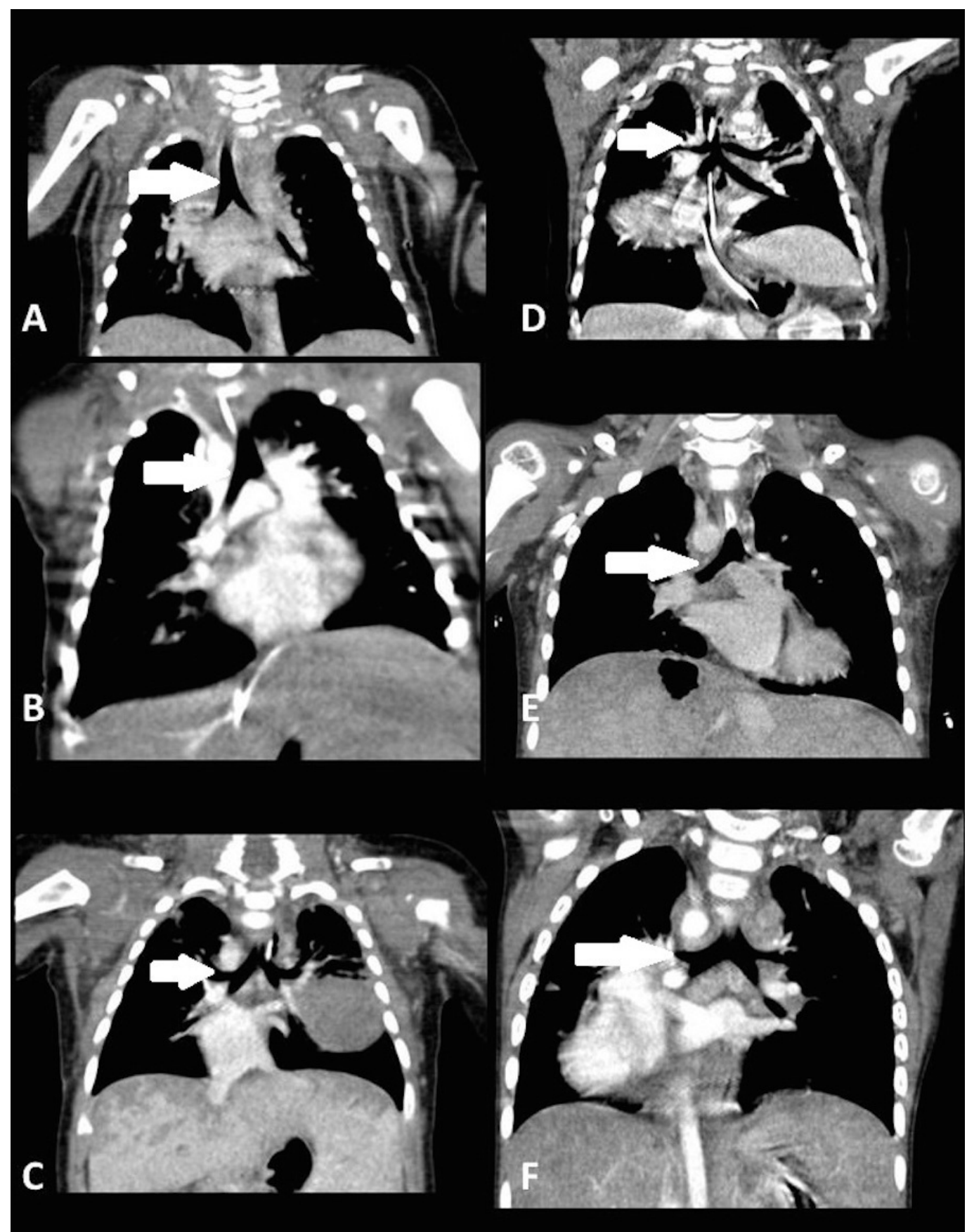

FIGURE 2: Bronchial isomerism

Computed tomography of the chest in the coronal plane from six different patients demonstrating bronchial isomerism. Panels $\mathrm{A}, \mathrm{B}$, and $\mathrm{C}$ demonstrate bronchial angles consistent with right-sided bronchial isomerism while panels $\mathrm{D}, \mathrm{E}$, and $\mathrm{F}$ demonstrate bronchial angles consistent with left-sided bronchial isomerism. Arrows point to the bronchial tree.

Isomerism of pulmonary lobation has also been noted, and usually is concordant with bronchial and atrial appendage isomerism. Chest radiographs, computed tomography of the chest, or magnetic resonance imaging of the chest can all be used to determine these features [26]. Direct identification of bronchial isomerism is important since it leads to further phenotypic delineation. As yet, however, it has not been established whether bronchial or pulmonary isomerism is associated with differences in respiratory outcomes. 


\section{Cureus}

\section{Immunologic abnormalities}

As we have already emphasized, in the past, heterotaxy was typically segregated into the subsets of so-called asplenia and polysplenia syndromes. From the stance of cardiac lesions, it is now clear that distinction on the basis of the presumed isomerism of the atrial appendages provides a better platform for segregation. It remains crucial, nonetheless, to specifically delineate splenic anatomy, the more so since discordances with bronchial and appendage morphology are frequent. It might be assumed that splenic anatomy is important in predicting splenic function, but this proves not to be the case. Patients with heterotaxy should always be assumed to have an abnormal splenic function, since even those with normally located and solitary spleens, or multiple spleens, can have functional asplenia [27-28].

While right isomerism is more frequently associated with the absence of the spleen and left isomerism is more frequently associated with the presence of multiple spleens, this is not invariably the case [7]. Thus, documenting specific splenic anatomy is important. In infants and children, abdominal ultrasound is a reasonable modality by which to assess splenic anatomy (Figure 3) [29]. In situations where there is inadequate visualization by ultrasound, or in adults, computed tomography is a viable alternative (Figure 4) [30-31].

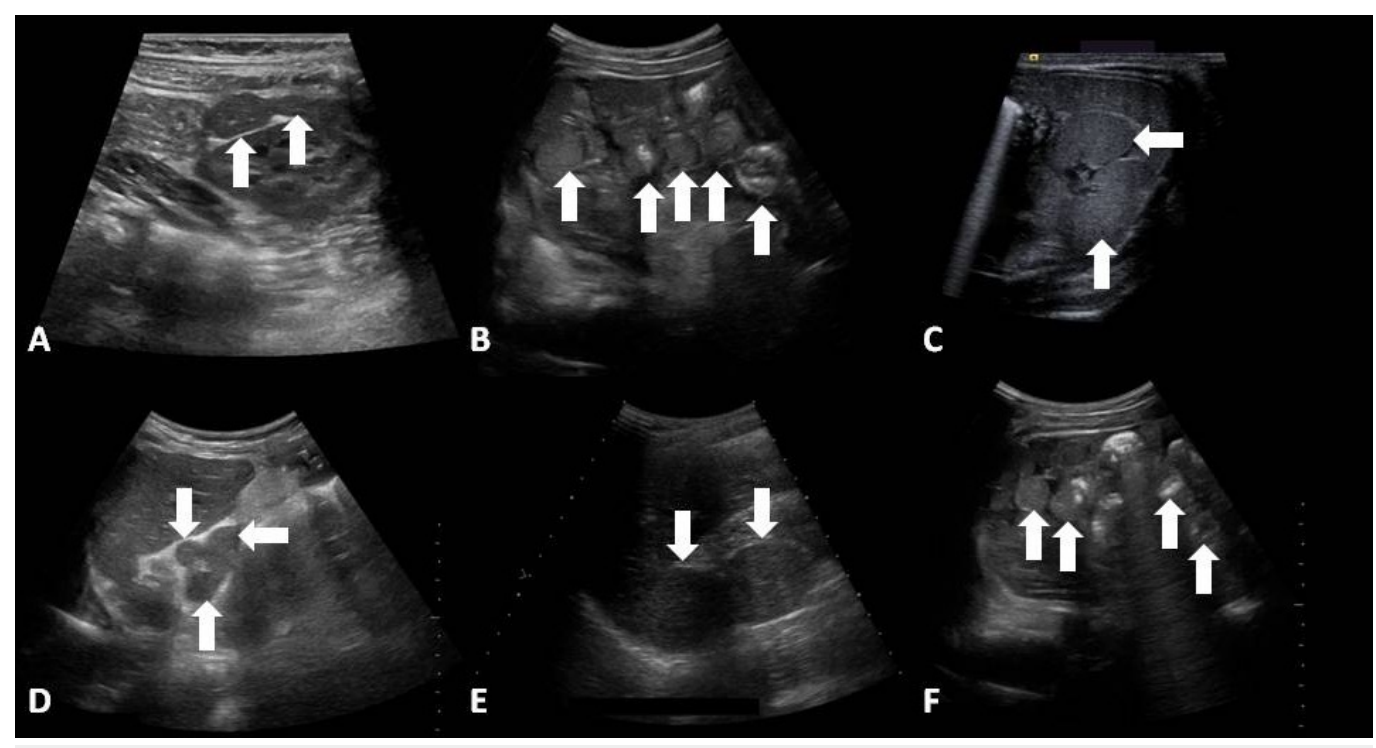

\section{FIGURE 3: Splenic anatomy by ultrasound}

Abdominal ultrasound imaging from six different patients demonstrating polysplenia. Splenic tissue in the setting of heterotaxy can be found in various parts of the abdomen with a varying number of spleens. 


\section{Cureus}

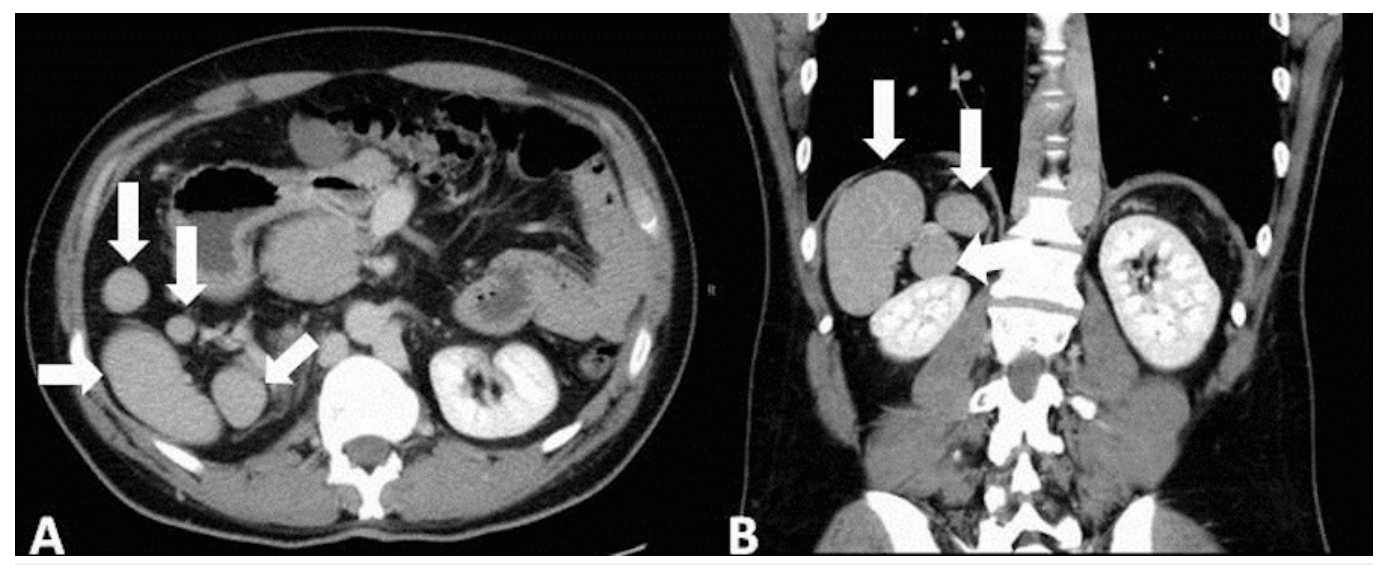

\section{FIGURE 4: Splenic anatomy by computed tomography}

Computed tomography of the abdomen from a single patient demonstrating polysplenia. Panel A depicts an axial slice in which multiple well-circumscribed soft tissue masses are identified with attenuation similar to that of a normal spleen in the right posterior abdomen. Panel B depicts a coronal slice which again demonstrates multiple spleens in the right upper abdomen.

Yet another modality is splenic scintigraphy, which can be performed using Technetium-99m (Tc-99m)-labeled denatured erythrocytes or Tc-99m-labeled sulfur colloid (Figure 5). This technique is able to identify splenic tissue as small as $1 \mathrm{~cm}$. Evaluation with Tc-99m-labeled denatured erythrocytes is preferred, as sulfur colloid can result in high liver uptake, thereby decreasing the sensitivity of the study. Splenic scintigraphy offers the advantage of being able to provide functional data in addition to anatomic data, particularly if performed with single photon emission computed tomography (SPECT)-CT [32-33]. A study comparing splenic scintigraphy with an abdominal ultrasound, nonetheless, showed that results of scintigraphy were often equivocal, and were obtained at the expense of exposure to radiation [34].

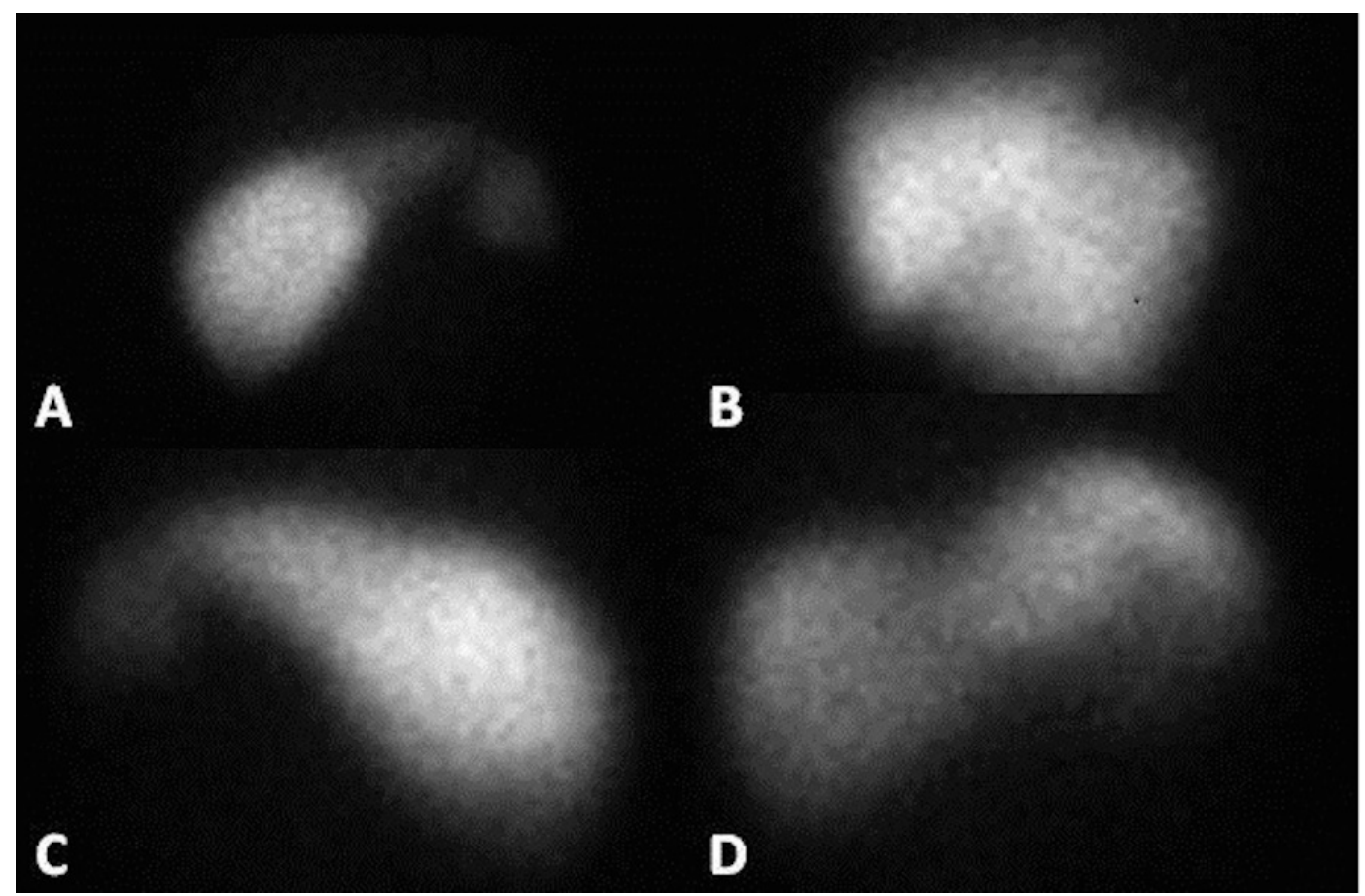

FIGURE 5: Splenic scintigraphy 
With these points in mind, therefore, an abdominal ultrasound should be the primary imaging modality used to assess splenic anatomy in infants and children. Should abdominal ultrasound not provide the necessary images, then computed tomography can be used, particularly in adults. If computed tomography offers equivocal findings, then splenic scintigraphy can be employed. For patients who undergo an abdominal ultrasound or computed tomography, the splenic function can be tested by means of identification of Howell-Jolly bodies or pitted red blood cells [35-36].

\section{Gastrointestinal abnormalities}

In addition to abnormal lateralization of the abdominal organs, pancreatic and hepatic malformations have also been noted to be associated with heterotaxy, with some finding a frequency of malrotation approaching $70 \%$ [37]. How best to diagnose malrotation in infants is still a matter of controversy. Some would routinely evaluate the upper gastrointestinal tract while others obtain imaging only in symptomatic infants. Identification of malrotation in an otherwise asymptomatic infant then leads to further debate as to the need for a prophylactic Ladd's procedure [38]. Such details are beyond the scope of our review.

Evaluation of the upper gastrointestinal tract, nonetheless, should always be undertaken when indicated (Figure 6). Interpretation, of course, requires an understanding of the varieties of malrotation. One classification suggests that rotation can be normal, mirror-imaged, exhibit a low position of the duodenojejunal junction with a wide mesentery, or exist with or without volvulus [37, 39]. In one series of 83 patients, 31\% had normal rotation, with none undergoing a Ladd's procedure, $48 \%$ had malposition of the duodenojejunal junction, with $32 \%$ undergoing an LADD's procedure, $9 \%$ had malrotation without volvulus, with $90 \%$ of these undergoing a Ladd's procedure, and $2 \%$ had malrotation with volvulus, all of these recommended for the Ladd's procedure. In $14 \%$, there was a mirror-imaged intestinal rotation, with none of these undergoing a Ladd's procedure [40]. The duodenojejunal junction is not necessarily abnormally positioned in all the types of malrotation. There is a lower risk of volvulus, however, when the junction is positioned to the left of the midline [41]. Both the type of malrotation and the position of the duodenojejunal junction, therefore, are of importance when determining clinical decisions. 


\section{Cureus}
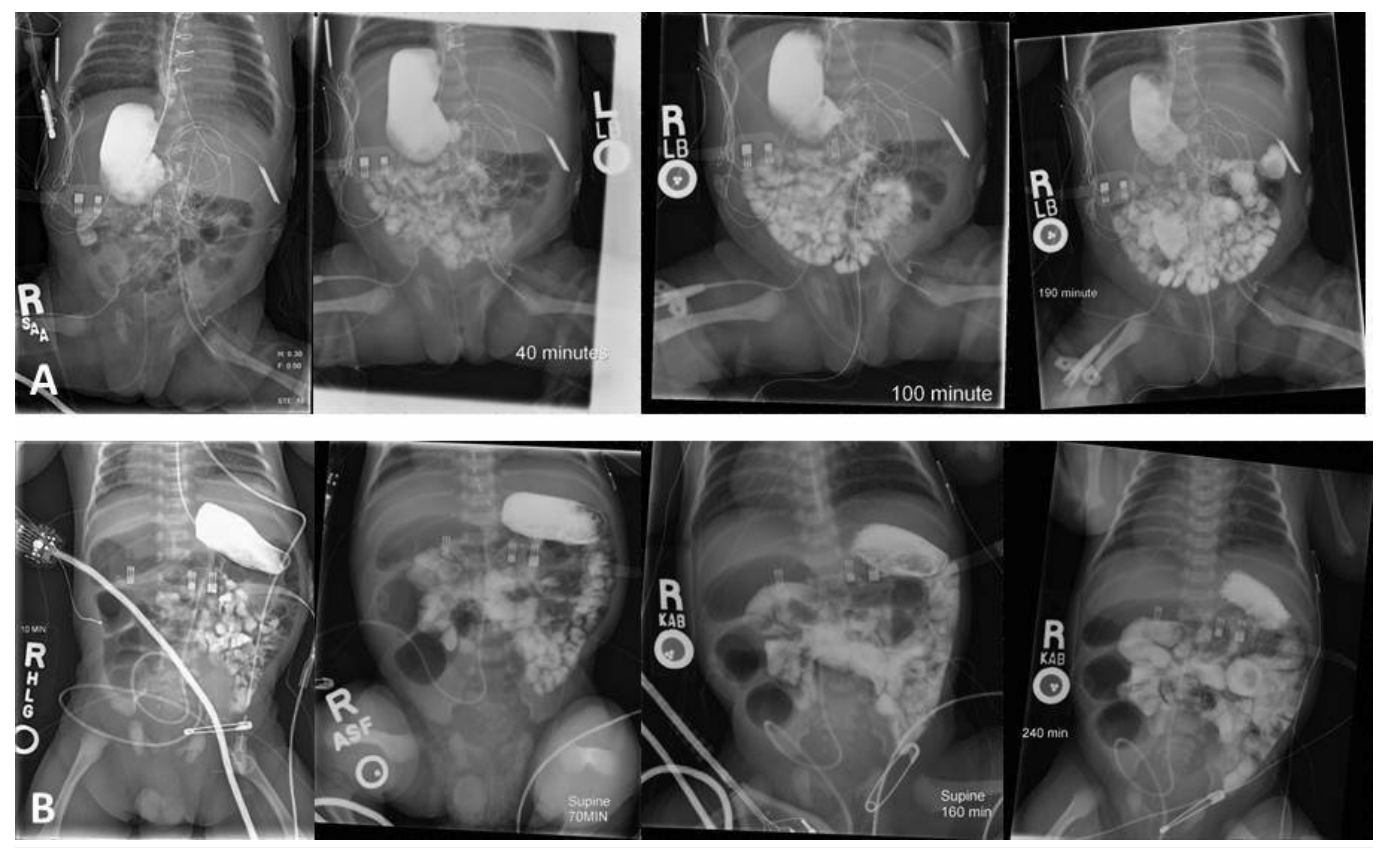

FIGURE 6: Intestinal malrotation

Abdominal radiographs from upper gastrointestinal series from two separate patients with malrotation without obstruction.

Pancreatic abnormalities are also associated with heterotaxy and include annular pancreas and partial agenesis, although their frequency is currently unknown [42-44]. Screening for pancreatic malformations does not need to be done in the absence of symptoms. Agenesis of the pancreas will more than likely be found incidentally on abdominal computed tomography. Further delineation, if needed, can be done via endoscopic retrograde cholangiopancreatography or magnetic retrograde cholangiopancreatography.

\section{Neurologic abnormalities}

Neurologic abnormalities are known to be part of heterotaxy, although the associations are not completely understood. Agenesis of the corpus callosum, holoprosencephaly, myelomeningocele, and neural tube defects have been reported [45-46]. Such associations were also found in the mouse model of heterotaxy [47]. Discussion of these abnormalities is beyond the scope of our review.

\section{Conclusions}

So-called "heterotaxy" involves multiple systems. Labels, such as "asplenia” or "polysplenia", are no longer adequate to account for the overall constellation of findings, nor is labeling in terms of "situs ambiguous". It is better simply to describe each system in explicit detail. This allows for anticipation of functional abnormalities, as well as any interventions that may be deemed necessary. From the stance of intracardiac lesions, the distinction of right as opposed to left isomerism will permit better comparison between patients, and will point to the need specifically to address the morphology of the atrial appendages. Such a distinction is most important when assessing genotypic variations.

\section{Additional Information}




\section{Disclosures}

Conflicts of interest: In compliance with the ICMJE uniform disclosure form, all authors declare the following: Payment/services info: All authors have declared that no financial support was received from any organization for the submitted work. Financial relationships: All authors have declared that they have no financial relationships at present or within the previous three years with any organizations that might have an interest in the submitted work. Other relationships: All authors have declared that there are no other relationships or activities that could appear to have influenced the submitted work.

\section{References}

1. Jacobs JP, Anderson RH, Weinberg PM, Walters HL 3rd, Tchervenkov CI, Del Duca D, Franklin RC, Aiello VD, Béland MJ, Colan SD, Gaynor JW, Krogmann ON, Kurosawa H, Maruszewski B, Stellin G, Elliott MJ: The nomenclature, definition and classification of cardiac structures in the setting of heterotaxy. Cardiol Young. 2007, 17:1-28. 10.1017/S1047951107001138

2. Loomba RS, Hlavacek AM, Spicer DE, Anderson RH: Isomerism or heterotaxy: which term leads to better understanding?. Cardiol Young. 2015, 25:1037-43.

10.1017/S1047951115001122

3. Uemura H, Ho SY, Devine WA, Kilpatrick LL, Anderson RH: Atrial appendages and venoatrial connections in hearts from patients with visceral heterotaxy. Ann Thorac Surg. 1995, 60:56169. 10.1016/0003-4975(95)00538-V

4. van Praagh R, David I, Wright GB, van Praagh S: Large RV plus small LV is not single RV . Circulation. 1980, 61:1057-59.

5. Bamforth SD, Bragança J, Farthing CR, Schneider JE, Broadbent C, Michell AC, Clarke K, Neubauer S, Norris D, Brown NA, Anderson RH, Bhattacharya S: Cited2 controls left-right patterning and heart development through a Nodal-Pitx2c pathway. Nat Genet. 2004, 36:1189-96. 10.1038/ng1446

6. Meno C, Ito Y, Saijoh Y, Matsuda Y, Tashiro K, Kuhara S, Hamada H: Two closely-related leftright asymmetrically expressed genes, lefty- 1 and lefty-2: their distinct expression domains, chromosomal linkage and direct neuralizing activity in Xenopus embryos. Genes Cells. 1997, 2:513-24.10.1046/j.1365-2443.1997.1400338.x

7. Uemura H, Ho SY, Devine WA, Anderson RH: Analysis of visceral heterotaxy according to splenic status, appendage morphology, or both. Am J Cardiol. 1995, 76:846-49.

10.1016/S0002-9149(99)80243-4

8. Bartz PJ, Driscoll DJ, Dearani JA, Puga FJ, Danielson GK, O'Leary PW, Earing MG, Warnes CA, Hodge DO, Cetta F: Early and late results of the modified fontan operation for heterotaxy syndrome 30 years of experience in 142 patients. J Am Coll Cardiol. 2006, 48:2301-5. 10.1016/j.jacc.2006.07.053

9. Ghawi H, Zghouzi MM, Emahbes TM, Awad SM: Prenatal diagnosis of isolated levocardia and a structurally normal heart: two case reports and a review of the literature. Pediatr Cardiol. 2013, 34:1034-37. 10.1007/s00246-012-0359-8

10. Imamura T, Momoi N, Go H, Ogasawara K, Sato M, Hosoya M: Rare case of isolated levocardia with polysplenia including normally structured lung without cardiac anomaly. Congenit Anom (Kyoto). 2011, 51:187-90. 10.1111/j.1741-4520.2011.00321.x

11. Fukuzawa J, Haneda T, Ishii Y, Kawashima E, Ogawa Y, Matsuhashi H, Kawamura Y, Imamoto $\mathrm{T}$, Tobise K, Onodera S: A case report of isolated levocardia without intracardiac anomalies associated with sick sinus syndrome. Jpn Circ J. 1993, 57:245-50. 10.1253/jcj.57.245

12. Loomba R, Shah PH, Anderson RH: Fetal magnetic resonance imaging of malformations associated with heterotaxy. Cureus. 2015, 7:e269. 10.7759/cureus.269

13. Loomba RS, Chandrasekar S, Shah PH, Sanan P: The developing role of fetal magnetic resonance imaging in the diagnosis of congenital cardiac anomalies: A systematic review. Ann Pediatr Cardiol. 2011, 4:172-76. 10.4103/0974-2069.84665

14. Loomba RS, Willes RJ, Kovach JR, Anderson RH: Chronic arrhythmias in the setting of heterotaxy: Differences between right and left isomerism. Congenit Heart Dis. 2015, (Epub ahead of print). 10.1111/chd.12288

15. Loomba RS, Aggarwal S, Gupta N, Buelow M, Alla V, Arora RR, Anderson RH: Arrhythmias in 
adult congenital patients with bodily isomerism. Pediatr Cardiol. 2015, (Epub ahead of print). 10.1007/s00246-015-1281-7

16. Loomba RS, Anderson RH: Letter to the editor regarding "Situs inversus with levocardia, infrahepatic interruption of the inferior vena cava, and azygos continuation: a case report". Surg Radiol Anat. 2015, 37:1289-90. 10.1007/s00276-015-1492-X

17. Loomba R: Thrombocytosis in the setting of isomerism and a functionally univentricular heart. Cureus. 2015, 7 :e383. 10.7759/cureus.383

18. Ferguson EC, Krishnamurthy R, Oldham SA: Classic imaging signs of congenital cardiovascular abnormalities. Radiographics. 2007, 27:1323-34. 10.1148/rg.275065148

19. Shen Q, Pa M, Hu X, Wang J: Role of plain radiography and CT angiography in the evaluation of obstructed total anomalous pulmonary venous connection. Pediatr Radiol. 2013, 43:82735. 10.1007/s00247-012-2609-6

20. Dyer KT, Hlavacek AM, Meinel FG, De Cecco CN, McQuiston AD, Schoepf UJ, Pietris NP: Imaging in congenital pulmonary vein anomalies: the role of computed tomography . Pediatr Radiol. 2014, 44:1158-68. 10.1007/s00247-014-3044-7

21. Van Mierop LH, Eisen S, Schiebler GL: The radiographic appearance of the tracheobronchial tree as an indicator of visceral situs. Am J Cardiol. 1970, 26:432-35. 10.1016/00029149(70)90743-5

22. Landing BH, Lawrence TY, Payne VC Jr, Wells TR: Bronchial anatomy in syndromes with abnormal visceral situs, abnormal spleen and congenital heart disease. Am J Cardiol. 1971, 28:456-62. 10.1016/0002-9149(71)90010-5

23. Partridge J: The radiological evaluation of atrial situs . Clin Radiol. 1979, 30:95-103. 10.1016/S0009-9260(79)80056-2

24. Partridge JB, Scott O, Deverall PB, Macartney FJ: Visualization and measurement of the main bronchi by tomography as an objective indicator of thoracic situs in congenital heart disease. Circulation. 1975, 51:188-96. 10.1161/01.CIR.51.1.188

25. Loomba RS, Pelech AN, Shah PH, Anderson RH: Determining bronchial morphology for the purposes of segregating so-called heterotaxy. Cardiol Young. 2015, (Epub ahead of print). 10.1017/S1047951115001195

26. Aune CN, Chatterjee B, Zhao XQ, Francis R, Bracero L, Yu Q, Rosenthal J, Leatherbury L, Lo CW: Mouse model of heterotaxy with single ventricle spectrum of cardiac anomalies . Pediatr Res. 2008, 63:9-14. 10.1203/PDR.0b013e31815b6926

27. Nagel BH, Williams H, Stewart L, Paul J, Stümper O: Splenic state in surviving patients with visceral heterotaxy. Cardiol Young. 2005, 15:469-73. 10.1017/S1047951105211320

28. Rodin AE, Sloane JA, Nghiem QX: Polysplenia with severe congenital heart disease and Howell-Jolly bodies. Am J Clin Pathol. 1972, 58:127-34.

29. Oleszczuk-Raschke K, Set PA, von Lengerke HJ, Tröger J: Abdominal sonography in the evaluation of heterotaxy in children. Pediatr Radiol. 1995, 25:S150-56.

30. Low JP, Williams D, Chaganti JR: Polysplenia syndrome with agenesis of the dorsal pancreas and preduodenal portal vein presenting with obstructive jaundice--a case report and literature review. Br J Radiol. 2011, 84:e217-20. 10.1259/bjr/27680217

31. Tawfik AM, Batouty NM, Zaky MM, Eladalany MA, Elmokadem AH: Polysplenia syndrome: a review of the relationship with viscero-atrial situs and the spectrum of extra-cardiac anomalies. Surg Radiol Anat. 2013, 35:647-53. 10.1007/s00276-013-1100-X

32. Combs LS, Gupta S, Mehta A: Evaluation of spleen in children with heterotaxia and congenital heart disease. Tenn Med. 2004, 97:161-63.

33. de Porto AP, Lammers AJ, Bennink RJ, ten Berge IJ, Speelman P, Hoekstra JB: Assessment of splenic function. Eur J Clin Microbiol Infect Dis. 2010, 29:1465-73. 10.1007/s10096-010-10491

34. Bakir M, Bilgic A, Ozmen M, Cağlar M: The value of radionuclide splenic scanning in the evaluation of asplenia in patients with heterotaxy. Pediatr Radiol. 1994, 24:25-28. 10.1007/BF02017654

35. McCarthy CF, Fraser ID, Evans KT, Read AE: Lymphoreticular dysfunction in idiopathic steatorrhoea. Gut. 1966, 7:140-48. 10.1136/gut.7.2.140

36. Casper JT, Koethe S, Rodey GE, Thatcher LG: A new method for studying splenic reticuloendothelial dysfunction in sickle cell disease patients and its clinical application: a brief report. Blood. 1976, 47:183-88.

37. Ferdman B, States L, Gaynor JW, Hedrick HL, Rychik J: Abnormalities of intestinal rotation in 
patients with congenital heart disease and the heterotaxy syndrome. Congenit Heart Dis. 2007, 2:12-18. 10.1111/j.1747-0803.2007.00066.x

38. Landisch R, Abdel-Hafeez AH, Massoumi R, Christensen M, Shillingford A, Wagner AJ: Observation versus prophylactic Ladd procedure for asymptomatic intestinal rotational abnormalities in heterotaxy syndrome: A systematic review. J Pediatr Surg. 2015, 50:1971-74. 10.1016/j.jpedsurg.2015.08.002

39. Mehall JR, Chandler JC, Mehall RL, Jackson RJ, Wagner CW, Smith SD: Management of typical and atypical intestinal malrotation. Journal of pediatric surgery. 2002, 37:1169-72.

10.1053/jpsu.2002.34465

40. Papillon S, Goodhue CJ, Zmora O, Sharma SS, Wells WJ, Ford HR, Upperman JS, Wang KS, Bushman GA, Kim R, Pierce JR: Congenital heart disease and heterotaxy: upper gastrointestinal fluoroscopy can be misleading and surgery in an asymptomatic patient is not beneficial. J Pediatr Surg. 2013, 48:164-69. 10.1016/j.jpedsurg.2012.10.033

41. Pockett CR, Dicken BJ, Rebeyka IM, Ross DB, Ryerson LM: Heterotaxy syndrome and intestinal rotation abnormalities: a survey of institutional practice. J Pediatr Surg. 2013, 48:2078-83. 10.1016/j.jpedsurg.2013.03.001

42. Ben Ahmed Y, Ghorbel S, Chouikh T, Nouira F, Louati H, Charieg A, Chaouachi B: Combination of partial situs inversus, polysplenia and annular pancreas with duodenal obstruction and intestinal malrotation. JBR-BTR. 2012, 95:257-60.

43. Yılmaz G, Akpınar SH, Alıcıŏlu B: Polysplenia syndrome detected after chest symptoms in two adult patients: case report and review of literature. Pol J Radiol. 2014, 79:311-14. 10.12659/PJR.890643

44. Jeong JH, Kim GH, Song GA, Lee DG, Moon JY, Cheong JH, Kim S: Polysplenia syndrome with congenital agenesis of dorsal pancreas presenting as acute pancreatitis and the role of endoscopic ultrasonography in its diagnosis. Korean J Gastroenterol. 2012, 60:47-51. 10.4166/kjg.2012.60.1.47

45. de Meeus A, Sarda P, Tenconi R, Ferrière M, Bouvagnet P: Blastogenesis dominant 1: a sequence with midline anomalies and heterotaxy. Am J Med Genet. 1997, 68:405-8. 10.1002/(SICI)1096-8628(19970211)68:4<405::AID-AJMG6>3.0.CO;2-K

46. Bonneau D, Maréchaud M, Odent S, Piegay I, Godard A, Amati P: Heterotaxy-neural tube defect and holoprosencephaly occuring independently in two sib fetuses. Am J Med Genet. 1999, 84:373-76. 10.1002/(SICI)1096-8628(19990604)84:4<373::AID-AJMG13>3.0.CO;2-8

47. Purandare SM, Ware SM, Kwan KM, Gebbia M, Bassi MT, Deng JM, Vogel H, Behringer RR, Belmont JW, Casey B: A complex syndrome of left-right axis, central nervous system and axial skeleton defects in Zic3 mutant mice. Development. 2002, 129:2293-302. 